\title{
Paisajes en el cine irlandés. El ejemplo de La Hija de Ryan
}

Landscapes in Irish film. The case of Ryan's Daughter

Abraham Domínguez Belloso

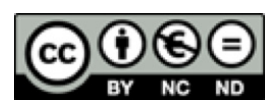

Esta obra está bajo una licencia Creative Commons Reconocimiento-No comercial-Sin Obra Derivada 


\title{
Paisajes en el cine irlandés. El ejemplo de La Hija de Ryan
}

\section{Landscapes in Irish film. The case of Ryan's Daughter}

\author{
Abraham Domínguez Belloso' \\ Universidad Alfonso X de Madrid (UAX) \\ España
}

Recibido: 20 de noviembre de 2017 Aprobado: 13 de diciembre de 2017

\begin{abstract}
Resumen
El artículo reflexiona sobre el paisaje en el cine que tiene como escenario natural Irlanda y su geografía física y humana, mostrando la carga simbólica y emocional que posee y que determina su propio lenguaje. Se aborda la experiencia paisajística en la película La hija de Ryan (Ryan's Daughter, David Lean, 1970), en la cual, el paisaje capaz de la trasformación humana y de los designios de los protagonistas en un sentimiento propio del movimiento romántico donde la naturaleza y el ser humano son parte de un mismo cosmos que se va espiritualizando. Será, además, un paisaje en constante movimiento que se explicará mediante los símbolos y las metáforas visuales que tanto le gustaban a su director David Lean, planteando la oscuridad del ser humano frente a la luz del entorno y huyendo de lo épico, dejando paso a lo dramático y permitiendo que el espectador pueda descubrir por sí mismo lo que aparece ante sus ojos.
\end{abstract}

Palabras clave: cine; paisaje; simbolismo; espacio geográfico; Irlanda

\begin{abstract}
The article reflects on landscape in films. In this particular case, the scenery is Ireland and its physical and human geography, showing the symbolic and emotional charge that has and determines its own language. The landscape experience is addressed in the film Ryan's Daughter (David Lean, 1970), being the landscape capable of human transformation and to design the leading characters.

1 Doctor en Cinematografía por la Universidad Rey Juan Carlos. Profesor asociado en la Universidad Isabel I y en la Universidad Alfonso X El Sabio, España. Correo electrónico: abraham.dominguezbelloso@gmail.com
\end{abstract}


The constant movement of the landscape will be explained by the symbols and visual metaphors that its director David Lean liked so much, raising from the darkness of human beings facing the light of the environment and fleeing from the epic, giving way to the dramatic and allowing the viewer to discover what appears before his eyes.

Keywords: cinema; landscape; symbolism; geographical space; Ireland 


\section{Introducción: paisaje y ser humano}

Hablar de paisaje es abordar los caminos de comunicación del ser humano con la naturaleza, con la esencia de sí mismo y con lo primigenio del ser humano. En el paisaje, lo poético hace su aparición a través de la experiencia estética y emocional que todos experimentamos, convirtiéndonos en entes mágicos capaces de soñar y de crear mediante símbolos un lugar catártico que habita en la región fantástica de nuestra mente. La llamada de lo salvaje se apoderó de las personas desde su origen y lo transformó dotando de magia sus acciones, sus representaciones artísticas y su vida entera. A través de la experiencia del paisaje, la vida del ser humano evolucionaría y lo convertiría en lo que es hoy. Podríamos debatir mucho acerca de la importancia en nuestras vidas y ver dónde, cuándo y a quiénes les influyó más, pero quizás carezca de importancia, pues la cuestión es el cómo con mucha más fuerza que las anteriores preguntas.

Cómo influyó e influye el paisaje en nuestra vida es una cuestión que quizás no muchas personas se planteen, simplemente lo contemplan desde un punto de vista estético o artístico e, incluso, emocional. Usualmente, se observa el paisaje sin darse cuenta que puede ser el hilo conductor de sus vidas, pues el hecho geográfico, unido al estético y al artístico, determinan de una manera clara la forma de ser de quienes lo habitan y de quienes lo gozan o lo sufren. El cine, heredero del hecho artístico, recoge de manera magistral lo aquí expuesto y clarifica de manera determinante para el espectador las influencias del paisaje y de sus elementos en los seres humanos, muchas veces de manera evidente, otras en clave simbólica, pero siempre cargados de belleza estética, pues el goce estético en la gran pantalla produce un profundo calado en el espectador.

Miguel de Unamuno fue un gran viajero y conocedor del paisaje español; varios de sus artículos referentes al paisaje se reflejaron en el diario El Sol, publicación liberal que se editaba en Madrid entre 1917 y 1936. Unamuno como paisajista literario, plasmó por escrito muchos artículos dedicados a sus pensamientos y meditaciones de la geografía ibérica y de sus metáforas. Eduardo Martínez de Pisón (1998) diferencia, en su libro Imagen del paisaje: La Generación del 98 y Ortega y Gasset, el significado metafórico del paisaje en la visión de Unamuno en tres sentidos: "como expresión de la integración y semejanza entre naturaleza y obra humana; para indicar la existencia de un sistema profundo, latente tras la forma del paisaje, y para mostrar la reciprocidad de éste con el espíritu" (p. 61-62). Como dice Miguel de Unamuno, "ese sueño con el paisaje quizás nos proporcione como individuos una cierta libertad del alma y solo se consigue a través de la visión del campo como metáfora" (González Egido, 1983 [2014], p. 130)².

2 Luciano González Egido (1983) en su libro Salamanca, la gran metáfora de Unamuno, cita la frase de Unamuno exponiendo, además, los lugares que visitaba y el sentimiento que le invadía según 
Los escenarios naturales son una fuente inagotable de inspiración y, a su vez, suponen un goce de inmortalidad para el alma y para la capacidad de soñar. Todos estos paisajes se sueñan en esas horas abismáticas en que, al separarse uno de la dulcísima ilusión de la sociedad de sus hermanos, de sus semejantes, de sus compañeros, cae de nuevo en la realidad de sí mismo (Unamuno, [1918] 2014, p. 24).

\section{Irlanda como escenario cinematográfico}

Irlanda es históricamente un lugar de encuentro cinematográfico donde el paisaje, dada su fuerza expresiva y su vida, adquiere un papel fundamental no solo como escenario, sino también como protagonista simbólico cargado de simbolismo y de metáforas visuales. John Ruskin, paisajista y escritor inglés, en su libro Modern Painters, hace la siguiente pregunta: "¿De veras el húmedo clima inglés es una de las cosas a las que querríamos que el Arte confiriese perpetuidad?". Respondió: "sí, sin duda"3. El paisaje como el arte se convierte en un referente revelador y poético capaz de traspasar la frontera hombre-psique y adentrarse en los contornos del alma humana, comenzando un viaje romántico donde el ser humano emprende un camino iniciático capaz de transformarle.

En Irlanda, el paisaje entabla un diálogo con el espectador y con los protagonistas, una conversación que se magnifica desde el primer momento en cada escena y se hace evidente a medida que el film avanza. El paisaje como escenario cinematográfico va a adquiriendo un tono místico cargado de espiritualidad. El profesor y paisajista Germán Hidalgo Hermosilla (1998), evoca a Ruskin para indicar que, "como el mismo Ruskin nos dice, se nos revela un nuevo paisaje, para nosotros poder, así, decir que a lo que se refiere Ruskin es a otro paisaje donde encontramos la destilación de la naturaleza misma: la vida" (1998, p. 13).

Irlanda y su paisaje se conciben cinematográficamente como una arquitectura natural alegórica de la vida que forma parte de la Creación y donde el pintoresquismo queda retratado en la relación del hombre con la geografía física, creando un mundo imaginario en el que la realidad va a ser reflejada de diversos modos, pero siempre siendo consciente del lugar que se habita. Un sentimiento trágico, como su propia historia, invade los argumentos que se desarrollan en los filmes rodados en el paisaje irlandés, desde Moby Dick (Moby Dick, John Huston, 1956) hasta El viento que agita la cebada (The Wind that Shakes the Barley, Ken Loach, 2006), pasando por títulos como Barry Lyndon (de Stanley Kubrick, 1975), El hombre tranquilo (The Quiet Man, John Ford, 1952), o El Prado (The Field, Jim Sheridan, 1990). El verdor de la hierba en contraste con el gris de un cielo casi siempre lluvioso, determina una

reflejan sus artículos (p. 130).

3 John Ruskin también ha sido citado en el libro El fin del arte de Donald Kuspit (2004, p. 128). 
atmósfera pesimista y trágica cargada de sentimientos y de emociones que espiritualizan al paisaje, pero que a su vez simboliza también la esperanza desde la visión occidental.

El sentido espacial del paisaje como una escenografía en constante movimiento establece un paralelismo entre los protagonistas, a través de grandes panorámicas, las cuales crean una dialéctica entre hombres y arquitectura natural. Esas atmósferas, en muchas ocasiones, beben de la pintura como en "Barry Lyndon"; en otras ocasiones de la literatura como en "Moby Dick", plantea una visión personal por parte de los directores que enriquece a la obra original y que genera un universo aparte dentro de la iconografía cinematográfica. Lo anterior se relaciona con la visión poética de hombres y mujeres en mitad de la épica paisajística enmarcada en la Gran Guerra, cargada de ideales y de metáforas que se alejan del concepto mediterráneo de luz y lo acercan al mito artúrico en atmósferas de nieblas, de tempestades o de lluvia que se nutren de la mitología celta.

Lo contemplativo es inherente en el cine que tiene como telón de fondo el paisaje irlandés y también en el paisaje inglés, cuya orografía salpicada de acantilados, prados, montañas y playas, invitan a la mente a mirar antes que a los ojos y a generar un encuentro personal con el cielo y con la tierra y a entregarse a una relación compleja y apasionada con lo que te rodea. La nostalgia por un paraíso personal que, en muchas ocasiones, se tornará en drama y en tragedia, en mitad de un paraíso terrenal cambiante y amenazador. La dimensión del paisaje en su relación humana se expresa de un modo humanista desde el Renacimiento aunando belleza original y goce estético y queda reflejado en el cine de David Lean.

Imagen 1. Escena de La hija de Ryan: El paisaje irlandés en su máximo esplendor en la película

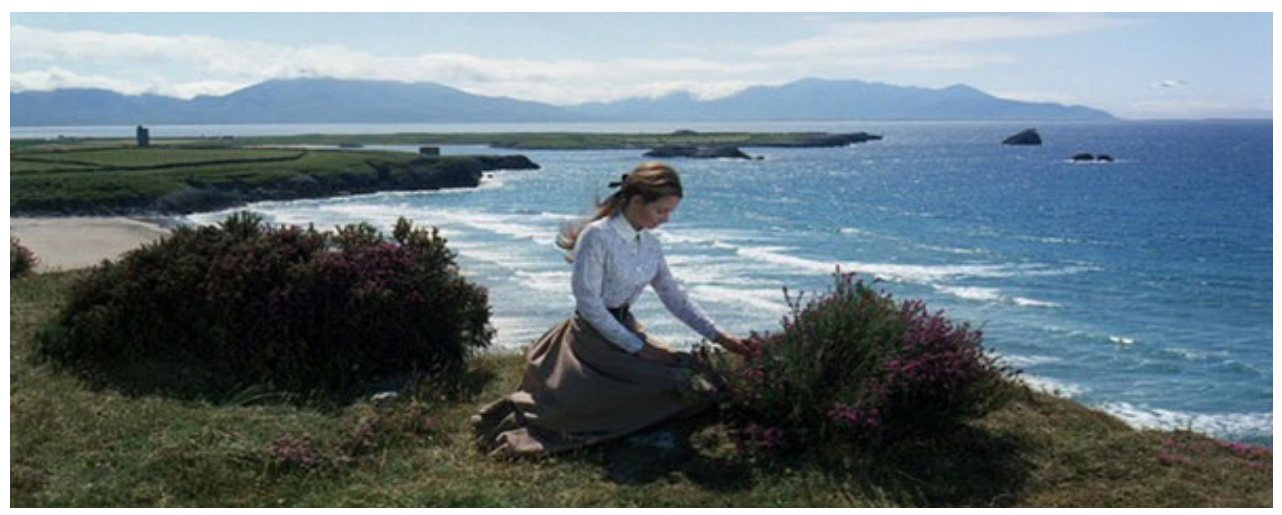

Fuente: Lean (1970). Fotograma de la película. 


\section{El ejemplo de La hija de Ryan}

La hija de Ryan (Ryan's Daugther, David Lean, 1970) presenta la naturaleza irlandesa a través de su paisaje y de su paisanaje, protagonistas solitarios y pensativos en mitad de los acantilados en una relación indisoluble que entronca con los principios del Romanticismo alemán y remite a los textos de Rafael Argullol (1991) en su libro La atracción del abismo. Un itinerario por el paisaje romántico al describir el cuadro de Caspar David Friedrich El monje contemplando el mar (1808-09). Expresa su apreciación del lienzo de la siguiente forma:

El monje se halla absorto. Su breve silueta es, apenas, un minúsculo accidente que no llega a turbar el predominio de los tres reinos. Tierra, mar, cielo, tres franjas infinitas empequeñecen la presencia del solitario; posiblemente también el gran ruido del silencio le anonada. La inmensidad le causa una nostalgia indescriptible y, asimismo, un vacío asfixiante. La antigua grandeza, perdida en el horizonte, le es retornada en forma de angustia: el mar se abre a sus pies como un fruto dulce y amargo (p. 1).

Imagen 2. El monje contemplando el mar [Óleo sobre lienzo]

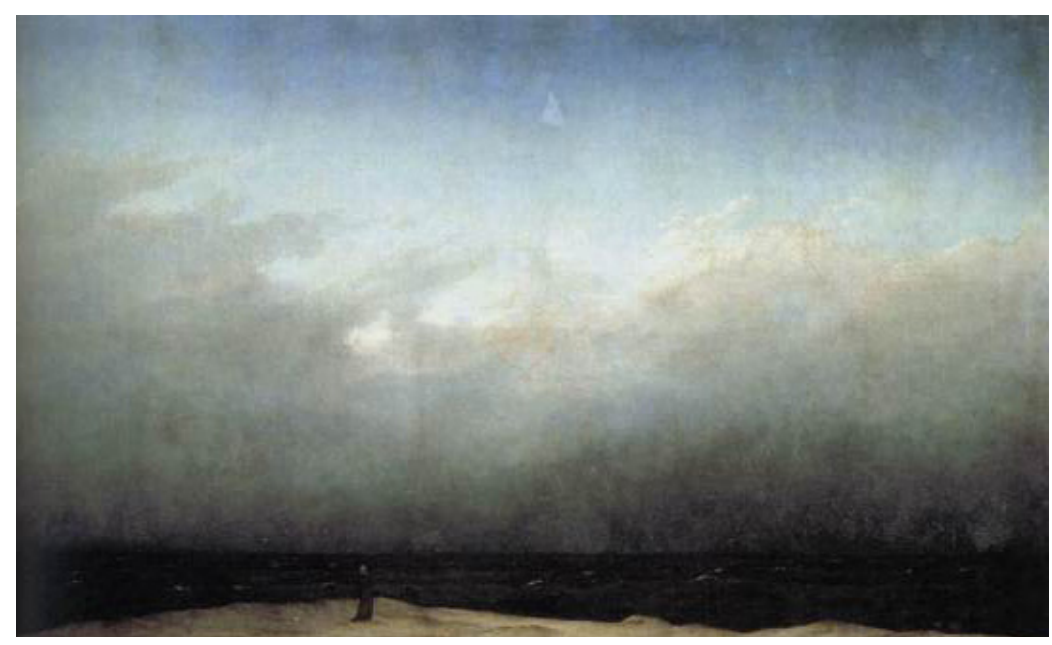

Fuente: Fiedrich, C.D. (1808-09). Berlín, Staatliche Museen de Berlín.

Haciendo alusión a las tres franjas del cielo, mar y tierra, La hija de Ryan intensifica planos y secuencias que parecen extraídos de la obra de C.D. Friedrich y que Rafael Moreno Cantero (1993) en su libro David Lean deja claro:

Un sentimiento panteísta se esconde tras cada acantilado, playa o nube de La hija de Ryan: la naturaleza divina adquiere movimiento desde los mismos créditos del film, en los cuales se fotografía el mismísimo génesis. Unas negras brumas llenan la pantalla de oscuridad (por la cual se filtra un leve resplandor dorado), que poco a 
poco se va aclarando por efecto de la luz solar y el fuerte sonido del viento (a veces a mayor volumen que la sensitiva partitura de Maurice Jarre): cuando finalizan los títulos, ha amanecido. Literalmente, durante ese tiempo dedicado al principio, se han separado tinieblas de luz. Solo una voluntad es capaz de tal hazaña, y su firma aparece inscrita sobre la misma por dos veces: "una película de David Lean" y "dirigida por David Lean". Él introduce la luz donde no la había y ubica en el mismo nivel Creador y Creación, comenzando así a desplegar el panteísmo antes indicado en un único y prolongado plano (p. 309).

Así nos muestra la película a los protagonistas, solitarios, absortos ante el abismo físico representado por los acantilados, y el abismo moral de sus vidas y de las circunstancias que las rodean, asemejándose las escenas a las de los cuadros del pintor romántico alemán C.D. Friedrich. El paisaje marca la pequeñez del hombre frente a la naturaleza y consiste, como diría Lord Byron, "en hacer del paisaje un estado de la conciencia" (Ainsa, 2001, p. 27). La Península de Dingle, al oeste de Irlanda, representa lo emocional del paisaje, vida y muerte, amor y odio, donde se puede como en palabras de Unamuno (1932), en su artículo "Manzanares arriba, o las dos barajas de Dios" publicado el domingo 26 de junio en el Diario El Sol de Madrid, "contemplar la naturaleza como historia y la historia como naturaleza, el paisaje como lenguaje y el lenguaje como paisaje" (p. 2). Ese lenguaje muestra más de lo que dice y su carga simbólica es evocadora; a través de él y como afirman Toni Luna e Isabel Valverde (2015):

Experimentamos emociones específicas en distintos contextos geográficos y vivimos emocionalmente los paisajes porque estos no son solo materialidades tangibles, sino también construcciones sociales y culturales impregnadas de un denso contenido intangible, a menudo solamente accesible a través del universo de las emociones (p. 14).

La carga emocional del paisaje en la película se presenta sugerente y viva, su voluptuosidad enraíza a sus protagonistas y se funde con el entorno. Cada plano se puede entender a través del sentimiento y en la misma línea que en Lawrence de Arabia (Lawrence of Arabia, David Lean, 1962), donde David Lean consigue el vínculo entre hombre y paisaje, pero esta vez alejado de lo épico e imbuido en lo dramático.

La tensión de lo dramático obedece a muchas causas que se encuentran en el paisaje, pues el entorno idílico y tranquilo cambia y se dramatiza con la llegada de la tormenta que como nexo de unión determina el cambio que la sociedad de la pequeña población en el film va a experimentar cuando los ingleses descubren el plan de ayuda del pueblo a los milicianos patriotas de Irlanda que culmina con la muerte de su líder. El eco de la primera guerra mundial junto a la dominación inglesa en la isla, enmarca a la historia en una tensión constante que acabará estallando y estrellándose con Rosy, la hija de Ryan. De nuevo el 
sentimiento como en el Romanticismo alemán convierte la experiencia del paisaje en la medida de todas las cosas, donde la naturaleza ejerce un poder de atracción que sitúa al hombre en una perspectiva que extrapola de algún modo la región fantástica de la mente y la capacidad de soñar, para devolverle a la más cruda realidad y a la nada frente al todo en mitad de un paisaje saturniano. Este paisaje contrasta con el sentir del paisaje bucólico que adornará toda la película y será este el único momento donde la naturaleza sea disconforme y terrible, ligada a un sentimiento trágico, preámbulo de lo que acontecerá posteriormente, donde el sufrimiento y la muerte no se hacen esperar. David Lean ya había creado tormentas en otras películas como Lawrence de Arabia, donde se refleja la relación de este hecho natural con el sentimiento y las emociones del protagonista:

En el film, los momentos de hundimiento del protagonista están visualizados en escenas que transcurren durante fuertes tormentas de arena. La primera, en el Sinaí, varios elementos refuerzan gradualmente esta sensación: el paisaje que aparece extraído de un film de ciencia-ficción al comienzo del viaje contrasta con la promesa de Lawrence de camas y sábanas limpias a su llegada al Cairo. La visión con resonancias bíblicas de "la columna de fuego" a la que Lawrence alude como distanciamiento de la realidad y la pérdida de la brújula durante el envite de la primera tormenta. La aparición de la tormenta en toda su furia lleva a la muerte de Daud, asociada con la primera crisis de identidad de Lawrence (Herráiz Ripoll, 2003, p. 58).

Imagen 3. Escena de La hija de Ryan: Escena de la tormenta en la película

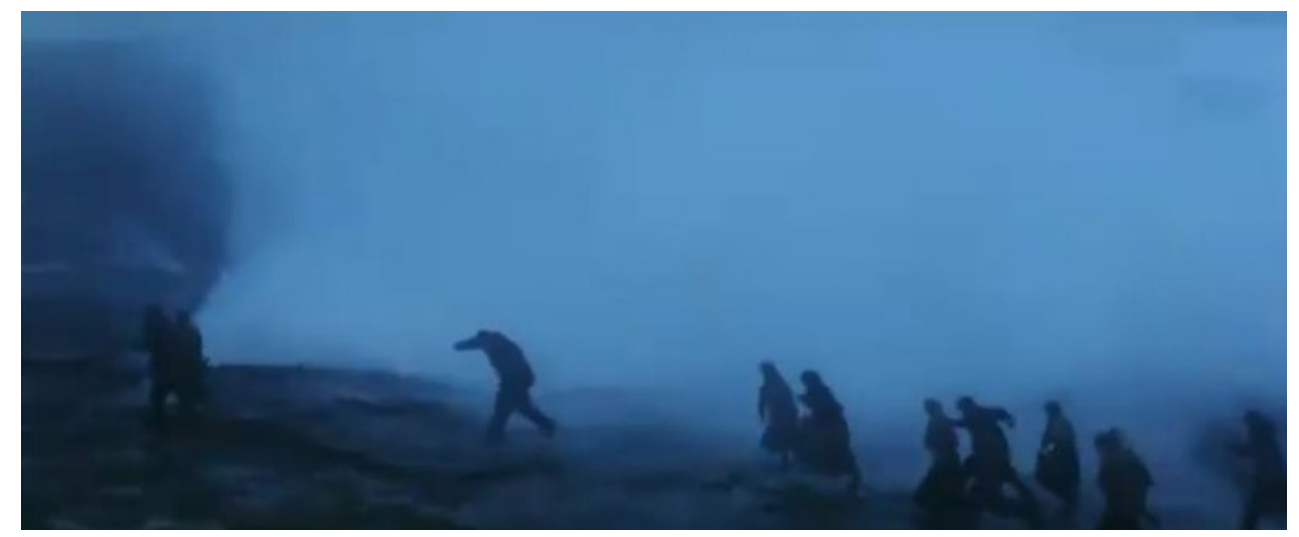

Fuente: Lean (1970). Fotograma de la película.

El paisaje se convierte, de esta manera, en un objeto en constante movimiento, se transforma, cambia, se comunica con el espectador mediante símbolos y metáforas visuales que nos hablan en clave y nos profetiza lo que acontece y lo que va a acontecer. La atmósfera, por tanto, construye la propia película y la va colocando en su propio espacio filmico, ordenándolo de tal modo que nada queda a la deriva y donde todo adquiere un 
sentido bello, metafórico y moral. Porque el paisaje también guarda su carga ética en la soledad, donde los dictámenes de la naturaleza están por encima de los de los hombres al estar dotados en el film por un componente divino y, por lo tanto, superior. Además, el planteamiento vital de los protagonistas cobra sentido al estar dotado de la fuerza de la narración y de la del propio escenario geográfico. La soledad en la película queda interiorizada en el paisaje, un lugar de gran belleza, pero a la vez misterioso, que juega un rol determinante: explica deseos en un territorio impuesto y no elegido.

El encuentro de los amantes siempre será al aire libre porque es ahí donde tendrán su espacio físico y sexual, donde la libertad en un tímido reflejo hace su aparición y donde la capacidad de los sentimientos y las emociones tienen su lugar. La naturaleza envuelve a los protagonistas en una búsqueda de sí mismos con o sin respuesta, pero actuando como protagonista y dando significado a cada hecho y realidad. Aventurándonos en los espacios geográficos que nos rodean descubrimos lo finito de nuestra existencia y la pequeñez del ser humano, el ego queda apartado a un lado y podemos comprender con mayor exactitud nuestra dimensión real en el infinito. Un infinito estructurado mediante símbolos que nos convierte en paisaje.

Imagen 3. Escena de La hija de Ryan: Plano de Rosy y el Mayor Dorian en el bosque

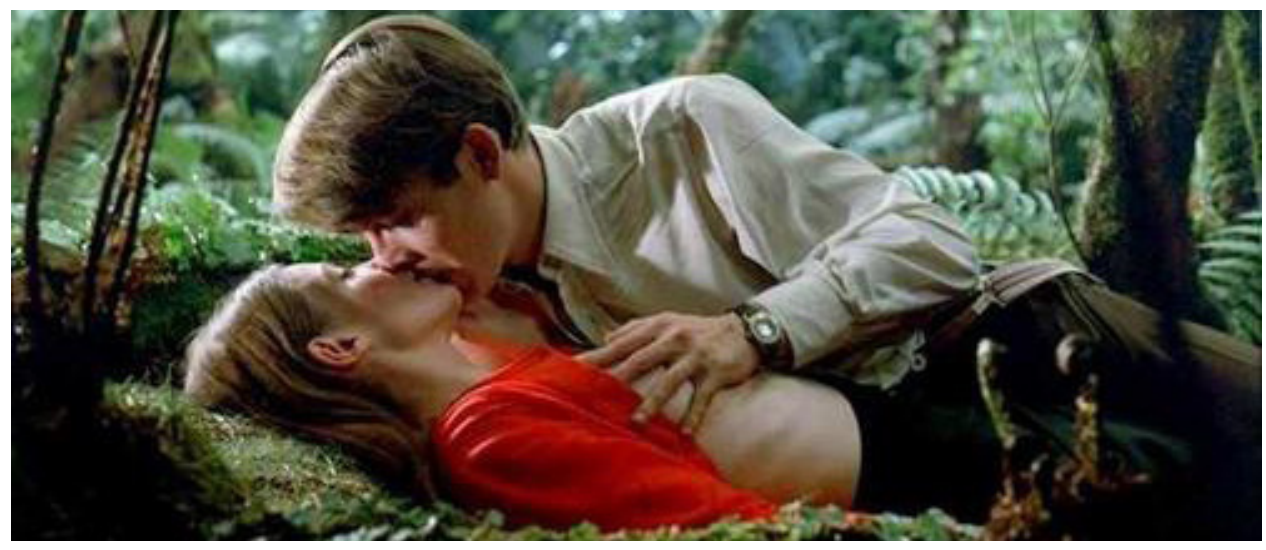

Fuente: Lean (1970). Fotograma de la película.

David Lean plantea los escenarios en todas sus películas con una delicadeza tal que todas las acciones relevantes se desarrollan a través del paisaje, que en su dualidad catártica ejerce como nexo de unión entre el amor y el drama, la pasión y la tragedia, con una luminosidad efervescente impropia de la meteorología irlandesa. Lean esboza la oscuridad del ser humano como ser frente a la luz del entorno natural, entorno que jamás permanece impasible a los vaivenes emocionales, traspasándolos y envolviéndolos en una atmósfera de símbolos que hay que saber leer e interpretar, definir y colocar en su lugar, pues el cine 
en esencia consiste en descubrir lo que aparece invisible ante nuestros ojos. Alejandro Herráiz Ripoll (1962) en su libro Guía para analizar. Lawrence de Arabia: David Lean, define la importancia del paisaje en la obra de David Lean a través de varias escenas de esta película:

Una serie de planos generales del paisaje compuestos siempre en horizontal, combinados con panorámicas y travellings puntúan el viaje. Los elaborados movimientos de cámara de este bloque tienen en todo momento la función de descubrimiento: la cámara en grúa, acompaña a los personajes elevándose hasta el borde de una duna, donde se extiende ante ellos una vasta llanura (p. 15).

No es casualidad que Rosy (Sarah Miles), la protagonista y esposa del maestro Charles Shaughnessy (Robert Mitchum), se entregue sexualmente al Mayor Doryan (Christopher Jones) en la naturaleza, lejos de todo y de todos, con una calma atmosférica impropia del país que metaforiza a la perfección la propia calma y tranquilidad en la que los amantes se van a encontrar momentáneamente en sus vidas.

Los planos generales de paisaje y las grandes panorámicas marcan la obra de Lean y como nos cuenta Marcos Ordónez (2012) donde narra en las crónicas de Perico Vidal, ayudante de dirección de la película:

Se ha convertido en un lugar común eso de "los paisajes son también protagonistas", pero en el caso de Lean era una verdad como un templo, y por eso rodaba en 65 milímetros, en Súper Panavisión. Paisajes gigantescos, enormes espacios abiertos. Muchos críticos se le echaron encima porque decían que era una escala demasiado grande para una historia que les pareció demasiado pequeña. Siempre hubo en las películas de Lean, ya lo hemos hablado, esa tensión entre lo íntimo y lo épico, pero quizás en La hija de Ryan se manifestó con una magnificencia más rotunda ese contraste. Mucho más, diría yo, que en Lawrence de Arabia y en Doctor Zhivago, que tampoco se quedaban cortas de paisajes (Ordóñez, 2012).

\section{Conclusión}

El paisaje supone un choque emocional con el alma de quien lo habita imponiendo su huella en cada escena y dejando paso a una realidad que la irrealidad del cine convierte en verdadera, pues nos hace identificarnos con los sentimientos de un personaje o de varios, y sobre todo, con sus estados anímicos. Encontrar un determinado paisaje como localización y desarrollo de un discurso narrativo concreto, supone beber de su esencia, de su tierra, de sus gentes, de su historia, de su pasado y de su presente, e Irlanda no podía ser indiferente al espectador ni a la producción.

Con una historia especialmente castigada y melancólica, los protagonistas de la película no podían permanecer impasibles al lugar que habitan, al hecho histórico y terrible de 
la Primera Guerra Mundial, a la dominación inglesa en la isla, a su paisaje y a su climatología. La tristeza propia y dada por las circunstancias invade a sus personajes en contraste con una climatología que en la película curiosamente aparece soleada y apacible, lejos de lo que realmente es Irlanda y su tiempo atmosférico. La paz del paisaje supone el punto antagónico con el paisanaje en constante conflicto interior y exterior. La teatralidad interior conjuga con la realidad natural necesitándose la una a la otra y quedando reflejada en cada plano y en cada secuencia. Los escenarios vacíos de humanidad física o con la mera representación de uno o dos personajes van a completar la película de una manera mística y espiritual, ya que es en la naturaleza donde el espíritu humano realmente queda vestido y alimentado, pues cual madre primigenia cobija a sus hijos, a sus pasiones y emociones. Esa apreciación Aliata y Silvestri (1994) la ponen de manifiesto:

Miradas: la historia del paisaje posee en el olvidado o menospreciado arte de ver uno de sus principales hilos conductores ... la historia del paisaje es la historia de las miradas: no en el sentido metafórico en que la palabra se utiliza en la historia de las mentalidades ... sino desde su acepción literal (p. 11).

David Lean demuestra ser un paisajista consagrado que concebía el cine como un ritual donde todo tenía que ser perfecto. El paisaje no podía ser menos y la plasticidad natural refleja su encuentro con la geografía física al servicio del cine como experiencia estética y mística, cargada de mensajes y de metáforas, pero también de sentimientos y pasiones que marcan un profundo camino hacia el conocimiento del entorno desde un punto de vista no solo turístico y de belleza, sino también de integración y de metafísica, donde el ser humano pueda cuestionarse absolutamente todo e incluso hallar respuesta y definir los significados de su propia existencia. El paisaje y la corporalidad van unidos en el camino a la eternidad, el espíritu humano se incorpora al paisaje y la conciencia es capaz de alimentarlo.

La naturaleza sin apenas profanar de la península de Dingle, en construcción de una sensibilidad receptiva que se nos muestra a los ojos a través del paisaje y donde no todos son capaces de ver más allá, en un sentido transgresor y diáfano, permite a unos pocos privilegiados el mayor de los goces posibles que no es otro que la comunión con el territorio que se pisa. Por eso, el paisaje se hace esencial en la película, porque por un lado limita la parte física, y por otra, la espiritual, alcanza una dimensión sobrenatural que atraviesa las fronteras de cualquier premisa humana, consciente y racional, con la fuerza suficientemente transformadora y purificadora en el hombre a través de la naturaleza donde cuerpo y espíritu se convierten en uno solo.

\section{Referencias}

Ainsa, F. (2001). ¿Jardín del Edén o infierno verde? Naturaleza y paisaje en la novela de la 
selva. Revista América, (29), 21-36.

Aliata, F. y Silvestri, G. (1994). El paisaje en el arte y en las ciencias humanas. Buenos Aires: Centro Editor de América Latina.

Argullol, R. (2012). La atracción del abismo. Barcelona: Acantilado.

Blázquez Mateos, E. (2000). Refinamiento y belleza en la obra de Luchino Visconti. AGR Coleccionistas de cine, 2(5), 18-41.

Fiedrich, C.D. (1808-09). El monje contemplando el mar [Óleo sobre lienzo]. Berlín, Staatliche Museen de Berlín.

González Egido, L. (1983). Salamanca, la gran metáfora de Unamuno. Salamanca: Ediciones Universidad de Salamanca

Herráinz Ripoll, A. (2003). Guía para ver y analizar: Lawrence de Arabia. David Lean (1962). Madrid: Octaedro

Hidalgo Hermosilla, G. (1998). El paisaje de la apariencia. Una historia del paisaje a partir de una conferencia de John Ruskin. DC PAPERS, revista de crítica y teoría de la arquitectura, (1), 21-33.

Kuspit, D. (2004). El fin del arte. Madrid: Ediciones Akal.

Lean, D. (director). (1970). La hija de Ryan [cinta cinematográfica]. Reino Unido: Metro-Goldwyn-Mayer.

Luna, T. y Valverde, I. (2015). Paisaje y emoción. El resurgir de las geografías emocionales. Barcelona: Observatorio del Paisaje de Cataluña / Universidat Pompeu Fabra

Martínez de Pisón, E. (1998). Imagen del paisaje. La Generación del 98 y Ortega y Gasset. Madrid: Caja Madrid

Moreno Cantero, R. (1993). David Lean. Madrid: Cátedra, Signo e imágenes / cineastas.

Ordóñez, M. (21 de diciembre de 2012). Big Time 14: En Irlanda con la hija de Ryan. El País. Recuperado http://blogs.elpais.com/bulevares-perifericos/2012/12/big-time-14-la-hijade-ryan-i.html

Ruskin, J. (1992). Modern painters (Vol. 5). Boston: Dana Estes \& Co.

Unamuno, M. (1917-1936). Diario El Sol. Madrid.

Unamuno, M. (26 de junio de 1932). Manzanares arriba, o las dos barajas de Dios. Diario El Sol.

Unamuno, M. (2014). Viajes y paisajes. Antología de crónicas de viaje. Madrid: La Línea del Horizonte. 